\title{
DIRETRIZES PARA CUIDADOS PALIATIVOS PRESTADOS A PACIENTES SUBMETIDOS A TRANSPLANTE DE CÉLULAS TRONCO HEMATOPOÉTICAS*
}

Vivian Maria Reksuaํ, Maria Cristina Paganini²

`Enfermeira. Mestre em Enfermagem. Enfermeira do Serviço de Transplante de Medula Óssea do Hospital de Clínicas da Universidade Federal do Paraná. Curitiba, PR, Brasil.

Enfermeira. Doutora em Enfermagem. Docente da Universidade Tuiuti do Paraná. Curitiba, PR, Brasil.

RESUMO: Estudo de abordagem qualitativa como o objetivo de propor diretrizes de cuidados paliativos aos pacientes submetidos a transplante de células tronco hematopoéticas. O cenário foi um hospital de ensino em Curitiba, estado do Paraná. O estudo foi desenvolvido em 2014 em duas fases: a primeira, exploratória, com entrevistas semiestruturadas com 12 enfermeiros. Da análise de conteúdo emergiram três temas: 1) Percepção sobre a experiência do cuidado paliativo no trabalho; 2) Sentido atribuído ao cuidado paliativo; 3) Interação profissional-família em cuidado paliativo. Na segunda fase foram realizados encontros com os enfermeiros, para propor e aprovar diretrizes aos cuidados paliativos. A definição de diretrizes pode facilitar e beneficiar a prática do cuidado, junto ao paciente, família e equipe multiprofissional, no final de vida e no enfrentamento da morte. DESCRITORES: Cuidado paliativo; Transplante de células-tronco hematopoiéticas; Enfermagem; Guia de prática clínica.

\section{PALLIATIVE CARE GUIDELINES FOR PATIENTS UNDERGOING HEMATOPOIETIC STEM CELL TRANSPLANTATION}

\begin{abstract}
Qualitative study aimed to propose palliative care guidelines for patients undergoing hematopoietic stem cell transplantation. The setting was a teaching hospital in Curitiba, state of Paraná. The study was conducted in 2014 in two stages: the first, exploratory stage, with semi-structured interviews with 12 nurses. Three topics emerged from content analysis: 1) Perception of palliative care in the workplace; 2) Sense assigned to palliative care; 3) Professional-family interaction in palliative care. In the second stage palliative care guidelines were proposed and approved in meetings with nurses. The definition of palliative care guidelines may facilitate and improve the palliative care delivered by multidisciplinary teams, with a positive impact on the quality of life of patients with a terminal disease and their families. DESCRIPTORS: Palliative care; hematopoietic stem cell transplantation; Nursing; Guide to clinical practice.
\end{abstract}

\section{DIRECTRICES PARA CUIDADOS PALIATIVOS PRESTADOS A PACIENTES SOMETIDOS A TRASPLANTE DE CÉLULAS MADRE HEMATOPOYÉTICAS}

RESUMO: Estudio de abordaje cualitativo cuya finalidad fue proponer directrices de cuidados paliativos a los pacientes sometidos a trasplante de células madre hematopoyéticas. El escenario fue un hospital de enseñanza en Curitiba, estado de Paraná. El estudio fue desarrollado en 2014 en dos fases: la primera, exploratoria, con entrevistas semiestructuradas con 12 enfermeros. Del análisis de contenido resultaron tres temas: 1) Percepción sobre la experiencia del cuidado paliativo en el trabajo; 2) Sentido del cuidado paliativo; 3) Interacción profesional-familia en cuidado paliativo. En la segunda fase, fueron realizados encuentros con los enfermeros para proponer y aprobar directrices a los cuidados paliativos. La definición de directrices puede facilitar y beneficiar la práctica del cuidado, con paciente, familia y equipo multiprofesional, en el fin de vida y en el afrontamiento de la muerte.

DESCRITORES: Cuidado paliativo; Trasplante de células madre hematopoyéticas; Enfermería; Guía de práctica clínica.

*Artigo extraído da Dissertação de Mestrado Profissional de Enfermagem intitulada: "Diretrizes para cuidados paliativos prestados a pacientes submetidos a transplante de células tronco hematopoéticas". Universidade Federal do Paraná, 2015. 


\section{INTRODUÇÃO}

O transplante de células tronco hematopoéticas (TCTH) é um "procedimento terapêutico que consiste na infusão de células tronco hematopoéticas (CTH) por via intravenosa, com a finalidade de restabelecer a normalidade funcional da medula óssea"1:472). É o tratamento que visa enxertar a célula progenitora hematopoética com o objetivo de corrigir um defeito quantitativo ou qualitativo da medula óssea ${ }^{(2)}$.

O TCTH é descrito como um procedimento altamente especializado, realizado em centros de excelência, para o tratamento de pacientes com doenças muitas vezes incuráveis. Dessa forma, a tarefa de cuidar do paciente é também complexa do ponto de vista emocional. Uma das maiores dificuldades encontradas pelos profissionais de TCTH é lidar com situações em que o agravamento do caso é inevitável. Sua formação privilegia o curar, no sentido de restabelecer a saúde. Contudo, na situação em que a cura nem sempre é possível, resta-lhes a difícil tarefa de cuidar sem necessariamente curar $^{(3)}$.

Assim, a morte, que é um risco relacionado ao TCTH, deve ser prevista no cuidado, bem como medidas de suporte para os enfermeiros, visto que muitas vezes sentem-se frustrados e fragilizados psiquicamente, podendo tornarse inábeis para lidar com ela. A consequência disto é que se evita falar do assunto, mesmo dentro de um local onde são tratados pacientes com patologias graves. Assim, se procede por temor de que sentimentos e reações inesperadas possam acontecer, trazendo sensação de falta de controle, algo que é tido como extremamente ameaçador por todos ${ }^{(4)}$.

Independente ou não de cenário de doença incurável, o papel assistencial do enfermeiro abrange cuidados integrais ao paciente, seus familiares e responsabilidades frente à equipe multiprofissional. Neste estudo, particularmente, trata-se das situações em que se esgotam as possibilidades terapêuticas e entram os cuidados paliativos. A intenção passa a ser a de prestar cuidado e não de tratar a doença, o que compõe a integralidade da assistência ${ }^{(5)}$.

Segundo a Organização Mundial da Saúde ${ }^{(6)}$, os cuidados paliativos consistem numa abordagem para melhorar a qualidade de vida dos pacientes e de seus familiares e o enfrentamento de doenças que oferecem risco de vida, por meio da prevenção e alívio do sofrimento. Isso inclui a identificação precoce e o tratamento da dor e de outros sintomas de ordem física, psicossocial e espiritual.

Fazem parte dos princípios de cuidados paliativos, dentre outros: promover o alívio da dor e de outros sintomas desagradáveis; afirmar e considerar a morte como um processo natural da vida; não acelerar nem adiar a morte; integrar os aspectos psicológicos e espirituais no cuidado ao paciente; oferecer sistema de suporte para auxiliar os familiares durante a doença do paciente e o luto; oferecer abordagem multiprofissional para focar as necessidades dos pacientes e de seus familiares; melhorar a qualidade de vida e influenciar positivamente o curso da doença ${ }^{(7)}$.

Nesta perspectiva, este estudo tem como objetivo propor diretrizes de cuidados paliativos aos pacientes submetidos a transplante de células tronco hematopoéticas.

\section{MÉTODO}

A pesquisa foi realizada em um hospital de ensino público, no Serviço de Transplante de Células Tronco Hematopoéticas, localizado na cidade de Curitiba, estado do Paraná, ao longo de 2014 e janeiro de 2015.

Foi realizada pesquisa de intervenção, em duas fases: pesquisa exploratória qualitativa, com 12 enfermeiros de uma unidade de TCTH, por meio de entrevista semiestruturada e, por critério de saturação de informação, submetida à análise de conteúdo; na segunda fase foram realizados dois encontros, na modalidade oficina, com enfermeiros da unidade, nos quais foi elaborada a proposta das diretrizes de cuidados paliativos.

Os dados das entrevistas foram coletados na unidade de internação, com enfermeiros com vínculo empregatício no hospital e que atuavam no TCTH. Foram excluídos aqueles que manifestaram desejo de não participar da pesquisa ou estiveram ausentes da unidade por motivos de licença e outros. Todos os entrevistados leram e assinaram o Termo de Consentimento Livre e Esclarecido (TCLE).

Todas as entrevistas foram codificadas com a letra E seguidas de um número de ordem: E1...E12. A análise dos dados da pesquisa se desenvolveu com base na descrição de conteúdo das mensagens analisadas, tendo como referencial metodológico a análise de conteúdo de $\operatorname{Bardin}^{(8)}$.

Esta pesquisa foi submetida ao Comitê de Ética em Pesquisa (CEP) da Universidade Federal 
do Paraná sob número 627.484, conforme determinação da Resolução do Conselho Nacional da Saúde. Observou-se o sigilo em relação à identificação dos participantes, respeitando a liberdade dos mesmos de desistirem a qualquer tempo da pesquisa e a privacidade.

\section{RESULTADOS}

Os entrevistados eram todos do sexo feminino, com faixa etária que variou de 28 a 62 anos de idade e tempo de formação de 5 a 29 anos.

Para os entrevistados, a dimensão do cuidado paliativo surgiu a partir de sua experiência, e foi possível evidenciar três temas, a partir de análise temática, mantendo o detalhamento, homogeneidade e pertinência. Os temas evidenciados foram: Percepções sobre a experiência do cuidado paliativo no trabalho; Significado atribuído ao cuidado paliativo; e Interação profissional-família em cuidado paliativo.

Os temas oriundos das categorias possibilitaram a análise estruturada do conteúdo, num nível formal, na qual refletem resultados significativos e fiéis, a fim de propor inferências e interpretações. Estes temas são apresentados a seguir.

\section{Percepções sobre a experiência do cuidado paliativo no trabalho}

Trabalhar com TCTH representa ao mesmo tempo uma conquista e um desafio. A conquista se expressa pela oportunidade de exercer atividades de enfermagem num setor altamente tecnológico. O desafio expressa-se pelo sentimento de superar a dor, o sofrimento e a frustração pela morte dos pacientes, conforme relato dos enfermeiros deste estudo.

Se a medula não pegar uma, duas e às vezes até três vezes, tem protocolos tem manuais e o paciente evolui para morte, não há nada afinal... é isso...(E1)

O que dá para dizer é que a gente fica com muito dó do paciente... o cuidado fica mais difícil de ser realizado porque a gente sabe que esse paciente não vai ter um futuro, não é como a gente esperava. (E11)

Outrossim, a definição clara e objetiva de que o paciente está sob cuidado paliativo é importante, pois o trabalho é multidisciplinar e a consonância entre todos os membros da equipe é fundamental. Em algumas falas os enfermeiros expressam a necessidade desta consonância entre a equipe, da falta da mesma e de falta de definição de quando e se efetivamente o paciente está sob cuidado paliativo.

Há necessidade de ter uma clareza maior de quando o paciente entra em cuidados paliativos, pois o que se percebe claramente e que esta posição na evolução do paciente demora para ser admitida. (E3)

Há, ainda, o modo como cada enfermeiro se relaciona com seu trabalho de maneira particular, que transparece nas falas, principalmente quando mencionam a relação com o paciente em cuidado paliativo, conforme transcrição a seguir:

Então em alguns momentos a gente se esquiva, também ficamos lá dizendo para o paciente que a pressão arterial está boa, enquanto todo o resto está ruim e a pressão agora é o de menos. (E1)

Destaca-se, nos discursos, a disposição que enfermeiros da pesquisa demonstram ao falar de mudança de paradigma frente ao cuidado paliativo ao paciente submetido à TCTH, bem como aqueles que enfrentam o cotidiano conforme a rotina estabelecida.

Podemos acolher melhor a família, não causar mais prejuizo ao paciente, disto eu sei. Temos todo o processo de tratamento, que nos cabe, integralmente, o resto eu acho que é consequência. (E2)

\section{Significado atribuído ao cuidado paliativo}

O cuidado paliativo fica entre limites opostos: de um lado o ideal de não abreviar a vida e do outro o de não prolongar o sofrimento. Então, se estabelece a necessidade de proporcionar qualidade de vida na morte. Os enfermeiros desta pesquisa têm clareza desta necessidade, conforme relato abaixo:

Eu entendo que esses cuidados devem levar em conta outros princípios que não só de cuidados hospitalares comuns, como exames, medicação, alimentação adequada entre outros e devem tratar de questões sociais e de ordem pessoal. (E3)

Porém, prevalece a necessidade de efetivar as ações de cuidados paliativos, pois os enfermeiros, apesar de possuírem suas próprias concepções acerca da vida e da morte, têm dificuldades de incorporar os procedimentos paliativistas em sua rotina, conforme constatado.

Aqui no serviço não existe um protocolo, não existe nenhum tipo de, de entendimento do que é esse cuidado paliativo.(E12)

Posso sentir que as questões relativas aos cuidados paliativos são "meio nebulosas" pra todos. (E2) 
Assim, enfermeiros que atuam nesta área convivem com a complexidade específica do TCTH e também têm que realizar ações pertinentes aos cuidados paliativos, conforme demonstrado nas falas dos enfermeiros.

Fazemos o possivel, medicar conforme o prescrito, medicação para dor, antitérmico e algum outro pra algum sintoma, ajudar na higiene e posteriormente realizar a higiene, a mesma coisa com a alimentação e hidratação, mas a dor é o que mais nos preocupa. (E8)

Contudo, associar os cuidados paliativos causa desconforto nos profissionais, como observamos a seguir, na colocação dos enfermeiros entrevistados.

Cuidar de pessoas é complexo, principalmente quando envolve a fragilidade, o sentimento do outro, em momentos de extrema dificuldade, como doenças graves e proximidade da morte. (E9)

Percebe-se, contudo, disponibilidade para mudanças, momento de acrescentar novas perspectivas para o cuidado paliativo, conforme entrevistado abaixo:

Se eu pensava até pouco tempo que o que se faz aqui em cuidados paliativos estava bom, venho percebendo que precisa melhorar. (E4)

Ao incorporar um modelo de cuidado paliativo não é possível pensar em estratégias para uma única categoria profissional, então este quesito também foi mencionado nas falas dos entrevistados.

É preciso prescrever os cuidados paliativos juntos, a enfermagem e os demais profissionais da equipe multidisciplinar. (E3)

É preciso que toda a equipe multiprofissional esteja engajada porque não adianta só nós fazermos a nossa parte, outros profissionais, todos precisam estar engajados. (E12)

\section{Interação profissional-família em cuidado paliativo}

Os enfermeiros que compartilharam sua experiência em cuidados paliativos colocam como indissociáveis o paciente e a família.

A gente tenta amenizar também as situações de desespero da família, da falta de preparo de todos para uma situação deste tipo, que muitas vezes só piora para o paciente. (E5)

Cuidado paliativo é abrangente, principalmente porque envolve a família do paciente de modo muito ativo com a enfermagem. (E9)
O desgaste emocional foi demarcado pelo sentido da impotência diante de situações de conflito que envolvem em certos momentos a família e os profissionais.

Então esses conflitos provocam muita angústia na gente. Quando se fica menos vezes em contato com o paciente é mais fácil, a gente não se envolve tanto eu acho, mas a enfermagem entra no quarto e conversa com o paciente, com o acompanhante, ninguém entra mudo e sai calado, é uma sensação de impotência. (ET)

Evidenciou-se uma pluralidade de sentimentos em relação aos cuidados paliativos prestados pelos enfermeiros, muitos sentimentos estão relacionados ao fato de permanecerem mais tempo em contato com o paciente e a família e não terem como evitar estabelecer um elo de proximidade durante a prestação do cuidado.

\section{Reuniões com enfermeiros para elaboração de Diretrizes para Cuidados Paliativos}

As oficinas com os enfermeiros ocorreram nos dias 26 de novembro e 03 de dezembro de 2014, datas previamente agendadas, com duração aproximada de 60 minutos, na sala de estudos da unidade pesquisada. Contou com a participação de 23 enfermeiros no primeiro encontro e 19 no segundo encontro.

No primeiro foi apresentado de forma sistemática o aspecto teórico-metodológico da pesquisa e o resultado das entrevistas. A partir de então se passou a discutir uma proposta de diretrizes para cuidados paliativos, apresentada pela pesquisadora, instrumentalizando a discussão com uma rápida apresentação do tema diretriz e cuidado paliativo, como cunho principal de entendimento das tendências a serem construídas. Foram utilizados recursos de retroprojetor, exposição oral e coordenação pelo pesquisador para melhor adequar o propósito do encontro.

A proposta final foi de manter o modelo de diretrizes apresentado pela pesquisadora, levar esta proposta para equipe multiprofissional e para a chefia da unidade. No segundo encontro, retomou-se a proposta preliminar, houve debates e propostas de ajuste. A discussão foi permeada pela informação, dada pela chefia de enfermagem e pela pesquisadora de que será instituída uma comissão multidisciplinar para ampliar a diretriz, com componentes da assistência de enfermagem entre outros, pois a visão do cuidado paliativo abrange outras dimensões. 
Os encontros proporcionaram reflexões entre os enfermeiros da necessidade de readaptação e reorganização no serviço, para incluir os cuidados paliativos em sua rotina e assim se ajustar à tendência mundial de produzir assistência integral neste campo de atenção em saúde.

\section{DISCUSSÃO}

Existe uma lacuna na formação dos profissionais de saúde no que tange ao preparo para lidar com as situações difíceis decorrentes do avanço da doença, as recidivas, a impossibilidade de cura e as perdas. Com isso, faz-se necessário desenvolver competências da equipe multiprofissional que se mantém próxima do paciente e sua família nos cuidados paliativos ${ }^{(9)}$.

No entanto, muitas vezes o cotidiano de trabalho impossibilita flexibilizar rotinas e normas, e os profissionais enfermeiros sentem-se pressionados por uma barreira de obstáculos que os leva a não compreender os cuidados paliativos como uma abordagem que contribui para o paciente viver melhor, propondo o paradigma do cuidado em detrimento da cura.

Deste modo, o grande desafio do cuidado paliativo no serviço de TCTH é incorporálo plenamente na rotina, pois paliar é indubitavelmente um conceito amplo que precisa estar inserido em todo serviço com todos seus princípios, respeitando conhecimentos específicos e habilidades ${ }^{(10)}$.

Seguindo este raciocínio é possível perceber os cuidados paliativos como uma filosofia de cuidado e também um sistema amplamente estruturado e organizado de prestação de cuidado, pois expande os modelos médicos de tratamentos tradicionais das doenças para incluir as metas de melhoria de qualidade de vida do paciente e da família, otimizando sua função, ajudando na tomada de decisões, oportunizando o crescimento pessoal e pode ser oferecido simultaneamente com os demais cuidados ${ }^{(11)}$.

Embora inúmeras discussões afirmem que os cuidados paliativos valorizam a vida e complementam as ações de saúde, frequentemente são relatados sentimentos de fracasso que impõem aos pacientes certo abandono, visto que a equipe não está preparada para esse fracasso emocional, causado também pelo temor dos sentimentos da família e do paciente sobre seu trabalho ${ }^{(12)}$.

Neste aspecto, as questões éticas que envolvem os cuidados paliativos não podem ser ignoradas. É fundamental reconhecer os limites da medicina e realizar um tratamento medindo os benefícios e o ônus do tratamento (beneficência) e avaliar os riscos e benefícios de cada decisão(13).

Esta assertiva propõe a reflexão de que a experiência do cuidado paliativo é uma realidade sombria. Fatores como tempo, inaptidão, até mesmo desestímulo levam enfermeiros que atuam em TCTH a negligenciarem os cuidados paliativos. É fundamental reconhecer as necessidades específicas da unidade e estabelecer estratégias de manutenção da cultura e filosofia de cuidados paliativos. Modelos e programa de diretrizes de ação podem recriar estratégias de ação que envolvam a instituição, os enfermeiros, as famílias e o paciente.

Entretanto, ao propor diretrizes aos cuidados paliativos em qualquer serviço, é relevante pensar tanto qualitativamente como quantitativamente, pois cada serviço possui características próprias e peculiares que precisam ser respeitadas, para que o cuidado paliativo se efetive e contribua com o setor.

Esta base trata da filosofia paliativista cujo mote é acrescentar qualidade de vida aos dias e não dias à vida ${ }^{(6)}$. Contudo, conceitos quanto à filosofia paliativista são relativamente novos em nossa sociedade, pois apenas na década de 1980 se iniciou a implantação de serviços de cuidados

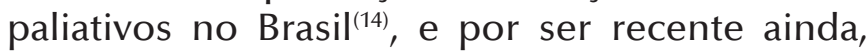
enfrenta resistência por parte dos profissionais de saúde, pois estes manifestam desconforto ao realizar este cuidado e fogem dele ${ }^{(15)}$.

Embora aconteça um movimento em prol do cuidado paliativo, ainda são imprescindíveis ações que atendam a demandas específicas como o TCTH e que possam atender aspectos subjetivos, destacando que o paciente participe do processo e das decisões em relação aos cuidados a ele dispensados.

Em outro aspecto, o TCTH é uma modalidade de tratamento realizado há trinta anos no Brasil, e apesar dos benefícios que pode trazer, considera-se como sendo terapêutica complexa e de risco, por possuir fatores que contribuem para aumentar a morbi-mortalidade do paciente ${ }^{(16)}$.

Neste cenário, a realização de cuidados paliativos deve ter como participante o enfermeiro, juntamente com toda equipe de enfermagem, atuando diretamente em todo o processo ${ }^{(17)}$. E, ao propor uma diretriz, espera-se sua incorporação na rotina do TCTH 
gradativamente, sendo compreendidas as fases de elaboração coletiva, baseada em material de apoio previamente selecionado, e com a participação de toda a equipe, bem como sejam realizados esclarecimentos para toda a equipe, sobre a temática, de forma aberta usando para tal o ambiente de trabalho, para que todos possam participar.

O último tema tratou da frágil relação entre a família, a equipe e o paciente; independente da ordem, esta tríade é indissociável. O impacto do sofrimento terminal e seu manejo, para os membros da família que presenciam o acontecimento, são multidimensionais. Estudos revelam que de $25 \%$ a $85 \%$ dos pacientes com doença terminal experimentam os sintomas associados ao sofrimento durante as horas ou dias antes de suas mortes, e suas famílias vivenciam com eles todo esse processo ${ }^{(18)}$.

O adoecimento e hospitalização se configuram como um evento particular que acaba por gerar crises e desestruturação para o sujeito e sua família. Quando a cura se torna impossível e o paciente passa a receber cuidados paliativos, é necessária uma estruturação por parte dos serviços para que este paciente que já vem de uma desestruturação possa ser identificado precocemente, ser avaliado corretamente e receba tratamentos específicos para dor e outros problemas de ordem física, psicossocial e espiritual.

O processo de cuidar não é necessariamente reconhecido pela cura ou tratamento de uma determinada patologia, mas também pelo conforto, pelo apoio e pela tentativa de diminuir o sofrimento do paciente e de seus familiares ${ }^{(19)}$. Nesta pesquisa os enfermeiros corroboram a assertiva de que a relação profissional-pacientefamília é inquestionável e o foco do cuidado não deve ser direcionado somente à pessoa em processo de terminalidade, mas a todo o grupo familiar, uma vez que a família também precisa de cuidado, pois se prepara para perder seu ente querido $^{(18)}$.

Neste contexto, foi possível observar que, quanto maior a situação de conforto e confiança, mais positiva pode ser a experiência e se estabelece assim uma relação de confiança entre a equipe e familiares $^{(20)}$. E ao relatar as experiências positivas mencionam a qualidade das relações travadas.

Embora seja reconhecida a eficiência das equipes que assistem pacientes em cuidados paliativos, que são especializadas ou treinadas por apresentarem melhores resultados no controle de sintomas físicos como dor, bem como dos sofrimentos psicossociais, e a capacitação desses necessita ser priorizada pelos serviços de saúde ${ }^{(21)}$. No entanto, no TCTH a integração entre cuidados curativos e cuidados paliativos precisa ser ressaltada para melhorar a qualidade do atendimento prestado. Afirmamos que uma diretriz que estabeleça o atendimento mais precoce possível integrado aos demais cuidados pode conduzir às estratégias ideais de atendimento.

\section{CONSIDERAÇÕES FINAIS}

Os enfermeiros que cuidam de pacientes em cuidados paliativos no TCTH compreendem este cuidado de formas diversas, sendo sua vivência construída e reconstruída durante sua vida profissional, que por sua vez está intrinsecamente relacionada à cura. Percebese que esses se sentem frustrados e impotentes com relação à morte, pois ela é culturalmente vista como fracasso e principalmente porque são essencialmente formados para combatê-la.

Ficou evidente, por meio das entrevistas dos enfermeiros participantes do estudo, que estes consideram uma diretriz de cuidados paliativos para os pacientes submetidos à TCTH uma ferramenta imprescindível para a promoção dos cuidados paliativos, pois ela permitirá esclarecer dúvidas e embasar cientificamente as ações, bem como fortalecer a atenção humanizada de forma que esta não se confunda com sentimentos pessoais sem Ihes acarretar sobrecarga emocional.

A limitação deste estudo relaciona-se a ampliação da diretriz agora estendida para a equipe multiprofissional, que terá continuidade mesmo após a finalização do estudo. Destaca-se a necessidade de estudos complementares que envolvam o tema, pois existe uma carência de estudos sobre a prática de cuidados paliativos em TCTH.

\section{REFERÊNCIAS}

1. Instituto Nacional de Cancer (INCA). Ações de enfermagem para o controle do câncer: uma proposta de integração ensino-serviço. 3. ed. Rio de Janeiro: INCA; 2008.

2. Pasquini R. Fundamentos e biologia do transplante de células hematopoéticas. In: Zago MA, Falcão RP, Pasquini R. Hematologia: fundamentos e prática. São Paulo: Ateneu; 2004. p. 913-34.

3. Rodrigues JC, Braga EM. Programa Cuidando do 
cuidador em Fortaleza, Ceará. In Carvalho MMMJ. Psico-oncologia no Brasil: resgatando o viver. São Paulo: Summus; 1998. p. 52-61.

4. Pereira DR, Cortez EA. Sofrimento psíquico na equipe de transplante de medula óssea. Rev. med. USP. 2014; 47(2):104-1.

5. Pessini L, Barchifontaine CP. Problemas atuais de Bioética. São Paulo: Loyola; 2012.

6. Organização Mundial da Saúde (OMS) [Internet]. Definição de cuidado paliativo; 2002 [acesso em 10 jan 2014]. Disponível: http://www.who.int/cancer/ palliative/definition/en

7. Instituto Nacional de Cancer (INCA). ABC do câncer: abordagens básicas para o controle do câncer. Rio de Janeiro: INCA; 2012.

8. Bardin L. Análise de conteúdo. São Paulo: Edições $70 ; 2010$.

9. Machado MFAS, Monteiro EMLM, Queiroz DT, Vieira VNFC, Barroso MGT. Integralidade, formação de saúde, educação em saúde e as propostas do SUS - uma revisão conceitual. Ciênc. saúde coletiva. 2007; 12(2):335-42.

10. Morrison S, Meier DE. Palliative Care. N Engl. J Med [Internet] 2004; 350 [acesso em 15 fev 2015] Disponível: http://palliativecare.yale.edu/student/361_37159_ PalliativeCare.pdf

11. National Consensus Project for Quality Palliative Care. Clinical Practice Guidelines for Quality for Palliative Care. Pittsburgh, PA: National Consensus Project; 2009.

12. Quintana AM, Kegker P, Santos MS, Diniz L. Sentimentos e percepções da equipe de saúde frente ao paciente terminal. Paidéia. 2006; 16:415-25.

13. Pessini L. Bioética na América Latina: algumas questões desafiantes para o presente e futuro. Bio e Thikos- Centro Universitário São Camilo; 2008.

14. Rodrigues IG, Zago MM, Caliri MH Uma análise do conceito de cuidados paliativos no Brasil. Mundo da Saúde. 2005; 29(2):147-57.

15. Hermes HR, Lamarca ICA. Cuidados paliativos: uma abordagem a partir das categorias profissionais de saúde. Ciênc. saúde coletiva. 2013; 18(9):2577-88.

16. Santos FSO. O desenvolvimento histórico dos cuidados paliativos e a filosofia hospice. In: Santos FSO. Cuidados paliativos: diretrizes, humanização e alívio dos sintomas. São Paulo: Atheneu; 2011. p.3-15.

17. Almeida CSL, Sales CA Marcon SS. O existir da enfermagem cuidando na terminalidade da vida: um estudo fenomenológico.Rev. Esc. Enferm. USP. 2014; 48(1):34-40.

18. Ferreira NMLA, Souza CLB, Stuchi Z. Cuidados paliativos e família. Rev. Ciênc. Méd. 2008; 17(1):33-42.

19. Soares MR, Rodrigues TG, Nascimento DA, Rosa MLS, Veigas SMF Salgado PO. Sentimentos, acolhimento e humanização em cuidados paliativos às crianças portadoras de leucemia. Fundamental care online. 2013; 5(3):354-63.

20. Kelly K, Thrane S, Virani R, Malloy P, Ferrel B. Expanding palliative care nursing education in California:The ELNEC Geriatric Project. Int J PalliatNurs. 2011; 17(4):188-94.

21. Higginson IJ, Evans CJ. What is the evidence that palliative care teams improve outcomes for cancer patients and their families? Cancer J. 2011; 16(5):423-35. 